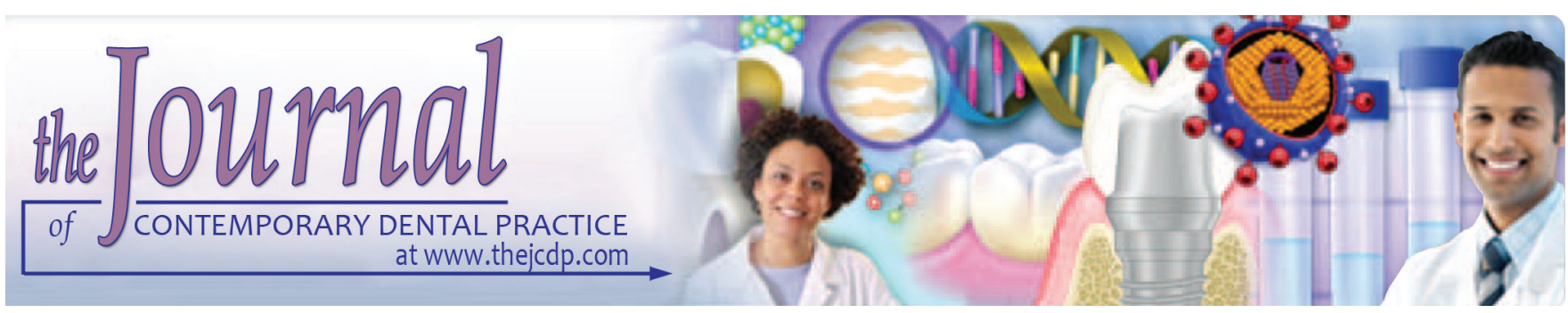

\title{
A Retrospective Analysis of Pulp Stones in Patients following Orthodontic Treatment
}

\author{
${ }^{1}$ Debkant Jena, ${ }^{2}$ Kandarpa Balakrishna, ${ }^{3}$ Sandeep Singh, ${ }^{4}$ Zuber A Naqvi, ${ }^{5}$ Archana Lanje, ${ }^{6}$ Nitin Arora
}

\begin{abstract}
Aim: The present study aimed to find prevalence of pulp stones in known South Indian orthodontic patients and to find correlation between pulp stones and patients who underwent orthodontic treatment as well as to reveal any differences due to gender, tooth type, and dental arches.
\end{abstract}

Materials and methods: The present retrospective study was carried out among 200 patients who underwent nonextraction orthodontic treatment. Maxillary and mandibular first and second premolar and molar teeth were selected for the purpose of the study using panoramic radiographs. A total of 3200 teeth of 200 patients were studied for the presence of pulp stones. Statistical analysis of the obtained data was carried out using Statistical Package for Social the Sciences (SPSS) version 22.0. Chi-square test was applied to find the significant value and $p \leq 0.05$ was considered as a significant value.

Results: In all, $11.5 \%$ of cases reported pulp stones before the commencement of the orthodontic treatment and $15.5 \%$ cases after completion of orthodontic treatment. Overall, $4 \%$ increase in cases were found which was statistically significant $(p<0.05)$;

\footnotetext{
${ }^{1}$ Department of Conservative Dentistry and Endodontics Institute of Dental Sciences, Siksha 'O' Anusandhan Deemed University, Bhubaneswar, Odisha, India

${ }^{2}$ Department of Pediatric Dentistry, Anil Neerukonda Institute of Dental Sciences, Visakhapatnam, Andhra Pradesh, India

${ }^{3}$ Department of Orthodontics and Dentofacial Orthopedics, Terna Dental College, Navi Mumbai, Maharashtra, India

${ }^{4}$ Department of Preventive Dental Sciences, College of Dentistry Majmaah University, Majmaah, Kingdom of Saudi Arabia

${ }^{5}$ Department of Oral Pathology, Maharana Pratap College of Dentistry \& Research Centre, Gwalior, Madhya Pradesh, India

${ }^{6}$ Department of Orthodontics and Dentofacial Orthopedics Manav Rachna Dental College, Faridabad, Haryana, India

Corresponding Author: Debkant Jena, Department of Conservative Dentistry and Endodontics, Institute of Dental Sciences, Siksha 'O' Anusandhan Deemed University Bhubaneswar, Odisha, India, Phone: +91889554795, e-mail: drdebjena@gmail.com
}

$5.1 \%$ of total number of teeth were evaluated in both arches before orthodontic treatment and $6.3 \%$ of teeth after orthodontic treatment revealed the presence of pulp stones. Maxillary first molar was found to be teeth with maximum number of pulp stones before and after orthodontic treatment

Conclusion: The present study reported the prevalence of pulp stones to be increased by $4 \%$ in the pre- and posttreatment radiographs, which was statistically significant. The study found the presence of pulp stones more in maxillary first molar and it was found to be teeth with maximum number of pulp stones before and after orthodontic treatment. However, further researches with larger samples are advisable.

Clinical significance: Dentists performing endodontic treatment among patients who have undergone orthodontic treatment should be aware about the increased chances of presence of pulp stones and thus to avoid hindrances encountered during extirpating the pulp, they should thoroughly study the radiographs beforehand.

Keywords: Orthodontic tooth movement, Pulp stones, Pulpal calcifications.

How to cite this article: Jena D, Balakrishna K, Singh S, Naqvi ZA, Lanje A, Arora N. A Retrospective Analysis of Pulp Stones in Patients following Orthodontic Treatment. J Contemp Dent Pract 2018;19(9):1095-1099.

Source of support: Nil

Conflict of interest: None

\section{INTRODUCTION}

Pulp stones are a group of calcifications which can be found discrete or diffuse in the pulpal tissue of healthy, diseased, and even in teeth which are not yet erupted. Stones may be present either freely within the dental pulp or embedded in or attached to dentin. The size may vary from a small microscopic particle to a large mass obliterating the pulp chamber. ${ }^{1}$ Calcifications in the dental pulp represent a phenomenon with varied occurrence and manifestation, presenting a topic of constant interest not only from the perspective of being a separate 
dental entity but also because of the fact that they have a therapeutic aspect. The therapeutic aspect demonstrates a greater importance for the reason that during endodontic therapy, they can make access difficult to the dental roots or sometimes completely impossible, and moreover, they can also be the cause for unjustified extraction of a tooth. ${ }^{2}$

A complex series of tissue reaction occurs during orthodontic tooth movement that has an effect on alveolar bone along with other related supporting structures as well as also involves dental pulp in a manner identical to stimulation caused by chemical or surgical management approaches. Literature reveals that the force application during orthodontic treatment may affect dental pulp like obliteration of pulpal tissue by formation of secondary dentin, alteration in pulpal respiration rate, internal root resorption, pulpal necrosis, cyst formation, as well as pulpal calcifications. $^{3}$

The variation in prevalence in different population groups is a matter of concern. The present study was planned and commenced to find the prevalence of pulp stones in known South Indian orthodontic patients using panoramic radiographs and to find correlation between pulp stones and patients who underwent orthodontic treatment as well as to reveal any differences due to gender, tooth type, and dental arches. If any correlation exists, it will provide information to assist the dentists during endodontic treatment of patients who have undergone orthodontic treatment to avoid hindrances encountered in extirpating the pulp during root canal treatments.

\section{MATERIALS AND METHODS}

The present retrospective study was carried among 200 patients who underwent nonextraction orthodontic treatment procedure in the Department of Orthodontics. A total of 200 cases were selected with age ranging from 14 to 26 years. The inclusion criteria for the selection of cases included panoramic radiographs (both pre- and posttreatment) of patients who underwent orthodontic treatment without any extraction of maxillary and mandibular first and second premolar and molar treatments, and without any loss of these teeth due to caries lesions. Any cases with poor-quality radiographs were excluded from the study. Any patients with a positive history of medical diseases were excluded from the study to prevent any bias due to systemic disorders.

Cases meeting the inclusion criteria were of minimum age 14 years and maximum age 26 years. Patients were not subjected to any radiations for the purpose of the study. Cases were selected over a period of 2 years. The panoramic radiographs of all the patients taken at the initiation of orthodontic treatment for the purpose of diagnostic records and at the completion of the orthodontic treatment were studied for analysis of pulp stones. Maxillary and mandibular first and second premolar and molar teeth were selected for the purpose of the study.

All panoramic radiographs were taken using an orthopantomogram machine. The average orthodontic treatment duration was $15.23 \pm 1.4$ months. A total of 3,200 teeth of 200 patients were studied. Required data were obtained from the department records. Interpretation of radiographs was done by two orthodontists separately. All the radiographs were processed manually using a visual method in a dark room under safe light. A tooth was recorded as having a pulp stone only when a definitive radiopaque mass was identified in the pulp chamber and a combined decision was made to either consider whether the tooth has pulp stones or not. Statistical analysis of the obtained data was carried out using SPSS versions 22.0 and chi-square test was applied to find significant values with $\mathrm{p} \leq 0.05$ which was considered as a significant value.

\section{RESULTS}

The present study found that among 200 cases, 54 were male patients and 146 were female patients; 6 out of 54 $(11.1 \%)$ male patients were diagnosed with pulp stones before the commencement of the orthodontic treatment and after completion of orthodontic treatment, 9 out of 54 $(16.6 \%)$ were found to have pulp stones. Among female patients, 17 out of $146(11.6 \%)$ were diagnosed with pulp stones before the commencement of the orthodontic treatment and after completion of orthodontic treatment, 22 out of $146(15 \%)$ patients were found to have pulp stones. Among 200 cases, 23 (11.5\%) cases reported pulp stones before the commencement of the orthodontic treatment and $31(15.5 \%)$ cases after the completion of orthodontic treatment (Table 1). Overall $4 \%$ increase in cases was found, which was statistically significant $(\mathrm{p}<0.05)$. Table 2 shows that maximum number of patients with increase in pulp stones was found in the age group 20 to 22 years.

On comparison of cases based on tooth- and archwise distribution (Table 3), 101 (6.3\%) out of 1,600 teeth showed the presence of pulp stones before orthodontic treatment, and $122(7.6 \%)$ teeth showed the presence of pulp stones after orthodontic treatment in maxillary arch; $64(4 \%)$ out of 1,600 teeth showed the presence of pulp stones before orthodontic treatment and 81 (5\%) teeth showed the presence of pulp stones after orthodontic treatment in mandibular arch; 165 (5.1\%) out of 3,200 teeth were the total number of teeth evaluated in both arches before orthodontic treatment and 203 (6.3\%) teeth after orthodontic treatment. Maxillary first molar was found to be teeth with maximum number of pulp stones before and after orthodontic treatment. 
A Retrospective Analysis of Pulp Stones in Patients

Table 1: Assessment of presence of pulp stones before and after orthodontic treatment

\begin{tabular}{|c|c|c|c|c|c|c|}
\hline Parameter & & Number & $\begin{array}{l}\text { Presence of pulp } \\
\text { stones before } \\
\text { orthodontic treatment }\end{array}$ & $\begin{array}{l}\text { Presence of pulp } \\
\text { stones after } \\
\text { orthodontic treatment }\end{array}$ & $\begin{array}{l}\% \text { pre- and } \\
\text { posttreatment }\end{array}$ & $p$-value \\
\hline \multirow[t]{2}{*}{ Gender } & Male & 54 & $6(11.1 \%)$ & $9(16.6 \%)$ & 4 & - \\
\hline & Female & 146 & $17(11.6 \%)$ & $22(15 \%)$ & & \\
\hline \multicolumn{2}{|c|}{$p$-value genderwise } & $>0.05$ & & & & \\
\hline \multicolumn{2}{|c|}{ Total no. of patients } & 200 & $23(11.5 \%)$ & $31(15.5 \%)$ & - & $<0.05$ \\
\hline \multicolumn{2}{|c|}{ Total no. of teeth } & 3200 & $165(5.1 \%)$ & $203(6.3 \%)$ & - & $<0.05$ \\
\hline
\end{tabular}

Table 2: Age group-wise comparison of dental pulp stones

\begin{tabular}{lllll}
\hline $\begin{array}{l}\text { Age group } \\
\text { (in years) }\end{array}$ & $\begin{array}{l}\text { Total no. of } \\
\text { patients }\end{array}$ & $\begin{array}{l}\text { Before } \\
\text { treatment }\end{array}$ & $\begin{array}{l}\text { After } \\
\text { treatment }\end{array}$ & $p$-value \\
\hline $14-16$ & 23 & $2(8.6 \%)$ & $3(13 \%)$ & $<0.05^{*}$ \\
$16-18$ & 39 & $4(10 \%)$ & $6(15 \%)$ & \\
$18-20$ & 37 & $4(10.8 \%)$ & $5(13.5 \%)$ & \\
$20-22$ & 54 & $7(11 \%)$ & $10(18.5 \%)$ & \\
$22-24$ & 37 & $4(10.8 \%)$ & $5(13.5 \%)$ & \\
$24-26$ & 10 & $2(20 \%)$ & $2(20 \%)$ & \\
$\begin{array}{l}\text { Total no. of } \\
\text { patients }\end{array}$ & 200 & $23(11.5 \%)$ & $31(15.5 \%)$ & \\
" Statistically signficant & & & &
\end{tabular}

\section{DISCUSSION}

In the current study, the prevalence of pulp stones was found to be $11.5 \%$, and after the completion of orthodontic treatment, it increased $15.5 \%$, i.e., with an increased prevalence of $4 \%$ in the pre- and posttreatment radiographs, which was statistically significant. In a study carried out in Turkey population using panoramic radiographs by Ertas et $\mathrm{al}_{1}^{3}$ pulpal stones were revealed in $3 \%$ of the teeth before orthodontic treatment and $5.2 \%$ of the teeth after completion of orthodontic treatment with increased prevalence of $2.2 \%$, which was statistically significant. No other literature regarding radiological evaluation of changes in dental pulp stone during orthodontic treatment was found.

Moreover, literature reports a great variation on occurrence of pulp stones among studied Indian populations.
Talla et $\mathrm{al}^{1}$ reported $25.9 \%$ prevalence of pulp stones among the studied population and $18 \%$ of teeth showed pulp stones in South Indian population. The study found a significantly higher pulp stones in the younger patients and also in patients with medical history of underlying systemic problems. Bains et $\mathrm{al}^{4}$ studied the presence of pulp stones and its association with systemic disorders in North Indian central Punjabi population and reported an overall prevalence of pulp stones as $41.8 \%$ and also found higher numbers of pulp stones in cardiovascular disease patients (38.89\%) than in patients with renal lithiasis and cholelithiasis. The present study excluded patients with a positive history of medical diseases to prevent any bias due to systemic disorders.

Data revealed from other parts of world also report a great variation in the presence of pulp stones. Colak et al ${ }^{5}$ identified pulp stones in $63.6 \%$ of the studied subjects and in $27.8 \%$ of the examined teeth in the Turkish population. Turkal et al ${ }^{6}$ found and reported pulp stones among $12.7 \%$ of studied population and reported a tooth prevalence of $2.1 \%$. Ranjitkar et $\mathrm{al}^{7}$ carried out a study in Australian population and found pulp stones in $46.1 \%$ of the studied subjects and $10.1 \%$ of the examined teeth. Ravanshad et $\mathrm{al}^{8}$ commenced a study in Iranian population and reported that $46.9 \%$ of the studied subjects had pulp stones and out of the 8,244 posterior teeth studied, they found pulp stones in the pulp chamber of 928 (11.25\%).

Table 3: Tooth- and arch-wise comparison of dental pulp stones

\begin{tabular}{|c|c|c|c|c|}
\hline \multicolumn{2}{|l|}{ Parameter } & \multirow{2}{*}{$\frac{\text { No. of teeth }}{400}$} & \multirow{2}{*}{$\begin{array}{l}\text { Presence of pulp stones } \\
\text { before orthodontic treatment } \\
4(1 \%)\end{array}$} & \multirow{2}{*}{$\begin{array}{l}\text { Presence of pulp stones after } \\
\text { orthodontic treatment } \\
4(1 \%)\end{array}$} \\
\hline Maxillary & First premolar & & & \\
\hline & Second premolar & 400 & $6(1.5 \%)$ & $8(2 \%)$ \\
\hline & First molar & 400 & $58(14.5 \%)$ & $71(17.8 \%)$ \\
\hline & Second molar & 400 & $33(8.2 \%)$ & $39(9.7 \%)$ \\
\hline \multicolumn{2}{|c|}{$\begin{array}{l}\text { Total no. of teeth with presence of pulp stones } \\
\text { in maxillary arch }\end{array}$} & 1600 & $101(6.3 \%)$ & $122(7.6 \%)$ \\
\hline \multirow[t]{4}{*}{ Mandibular } & First premolar & 400 & $2(0.5 \%)$ & $2(0.5 \%)$ \\
\hline & Second premolar & 400 & $11(2.7 \%)$ & $14(3.5 \%)$ \\
\hline & First molar & 400 & $32(8 \%)$ & $41(10.2 \%)$ \\
\hline & Second molar & 400 & $19(4.7 \%)$ & $24(6 \%)$ \\
\hline \multicolumn{2}{|c|}{$\begin{array}{l}\text { Total no. of teeth with presence of pulp stones in } \\
\text { mandibular arch }\end{array}$} & 1600 & $64(4 \%)$ & $81(5 \%)$ \\
\hline \multicolumn{2}{|c|}{ Total no. of teeth evaluated in both arches } & 3200 & $165(5.1 \%)$ & $203(6.3 \%)$ \\
\hline \multicolumn{2}{|l|}{$p$-value } & $<0.05$ & & \\
\hline
\end{tabular}


These differences in the prevalence of presence of pulp stones between various populations may be attributed to geographical differences as well as ethnic variations among different populations.

The present study found no variation and no significant differences with respect to gender which is in accordance with Gulsahi et al, ${ }^{9}$ Ranjitkar et $\mathrm{al}^{7}{ }^{7}$ and Sisman et al. ${ }^{10}$ However, in contrast to the present study, higher pulp stones were found in females in studies commenced by Ravanshad et al, ${ }^{8}$ Turkal et al, ${ }^{6}$ and Colak et al. ${ }^{5}$

The current study found the presence of pulp stones more in maxillary first molar and it was found to be teeth with maximum number of pulp stones before and after orthodontic treatment. This can be attributed to the fact that molars are the largest teeth in the arch with strongest chewing force in the arch and have a better blood supply to the pulpal tissue, which can result in more precipitation for calcification. ${ }^{10}$

The two frequently employed methods are histological and radiographic approaches to detect pulp stones, and radiographic method using panoramic radiographs was employed in the present study due to limited applicability of histological method in clinical settings. ${ }^{11}$

Literature indicates varied data on the etiology of pulp stones that comprise inductive communications between epithelial and pulpal tissue, pulp degeneration, age, nanobacteria, idiopathic factors, genetic predisposition, circulatory disturbances in the pulp, fluoride supplementation, orthodontic tooth movements, and Marfan syndrome. Moreover, their formation may be correlated with long-standing irritants, such as caries, deep fillings, and chronic inflammation. Furthermore, pulp stones are also considered as a feature of an irritated pulp, endeavoring itself to repair. ${ }^{4}$ Beres et $\mathrm{al}^{12}$ investigated the physicochemical properties of the mineralized tissues of teeth to elucidate the pathologic origin of pulp stones and identified $\mathrm{P}, \mathrm{Ca}, \mathrm{Cu}, \mathrm{Zn}$, and $\mathrm{Sr}$ within dentin and pulp stones. $\mathrm{Zn}$ and $\mathrm{Cu}$ concentrations were higher in pulp stones and carious dentin compared with healthy dentin.

Ezoddini-Ardakani et $\mathrm{al}^{13}$ reported diagnostic importance of dental pulp stones in the early diagnosis of ischemic heart diseases. The study reported that teeth ratio with pulp stone to total teeth $\geq 0.2$ presents a good tool for early detection of cardiovascular diseases and thus recommended that the dentists, who advise panoramic radiographs for the treatment of patients, should evaluate teeth for the presence of pulp stones and should refer the patients to cardiologists for consultation in the case of the presence of several pulp stones.

The present study had a limitation of small sample size and was conducted in population of a particular region.
Further studies with larger samples in various population groups are recommended.

In dental treatment prospect, attached stones possess hindrances in the way of exploring instruments by engaging or deflecting their tip during endodontic procedure, thus preventing their easy movement inside the canal. ${ }^{14,15}$

\section{CONCLUSION}

The present study reported the prevalence of pulp stones to be increased to $4 \%$ in the pre- and posttreatment radiographs, which was statistically significant. The study found the presence of pulp stones more in maxillary first molar and it was found to be teeth with maximum number of pulp stones before and after orthodontic treatment. Dentists during endodontic treatment of patients who have undergone orthodontic treatment should be more conscious for the presence of pulp stones, and thus, to avoid hindrances encountered during extirpating the pulp, they should thoroughly study the radiographs beforehand. However, further researches with larger samples are advisable.

\section{REFERENCES}

1. Talla HV, Kommineni NK, Yalamancheli S, Avula JSS, Chillakuru D. A study on pulp stones in a group of the population in Andhra Pradesh, India: an institutional study. J Conserv Dent 2014 Mar-Apr;17(2):111-114.

2. Aleksova P. Prevalence of pulp stones in molars regarding the dental arches. Int J Sci Res 2015 Jul;4(7):1990-1993.

3. Ertas ET, Veli I, Akin M, Ertas H, Atici MY. Dental pulp stone formation during orthodontic treatment: a retrospective clinical follow-up study. Niger J Clin Pract 2017 Jan;20(1):37-42.

4. Bains SK, Bhatia A, Singh HP, Biswal SS, Kanth S, Nalla S. Prevalence of coronal pulp stones and its relation with systemic disorders in northern Indian central Punjabi population. ISRN Dent 2014 Apr;2014:617590.

5. Colak H, Celebi AA, Hamidi MM, Bayraktar Y, Çolak T, Uzgur R. Assessment of the prevalence of pulp stones in a sample of Turkish Central Anatolian population. Sci World J 2012;2012:804278.

6. Turkal M, Tan E, Uzgur R, Hamidi M, Çolak H, Uzgur Z. Incidence and distribution of pulp stones found in radiographic dental examination of adult Turkish dental patients. Ann Med Health Sci Res 2013 Oct;3(4):572-576.

7. Ranjitkar S, Taylor JA, Townsend GC. A radiographic assessment of the prevalence of pulp stones in Australians. Aust Dent J 2002 Mar;47(1):36-40.

8. Ravanshad S, Khayat S, Freidonpour N. The prevalence of pulp stones in adult patients of Shiraz Dental School, a Radiographic Assessment. J Dent (Shiraz) 2015 Dec;16(4): 356-361.

9. Gulsahi A, Cebeci AI, Ozden S. A radiographic assessment of the prevalence of pulp stones in a group of Turkish dental patients. Int Endod J 2009 Aug;42(8):735-739.

10. Sisman Y, Aktan AM, Tarım-Ertas E, Çiftçi ME, Şekerci AE. The prevalence of pulp stones in a Turkish population. 
A radiographic survey. Med Oral Patol Oral Cir Bucal 2012 Mar;17(2):e212-e217.

11. Udoye CI, Sede MA. Prevalence and analysis of factors related to occurrence of pulp stone in adult restorative patients. Ann Med Health Sci Res 2011 Jan-Jun;1(1):9-14.

12. Beres F, Isaac J, Mouton L, Rouzière $S$, Berdal A, Simon S, Dessombz A. Comparative physicochemical analysis of pulp stone and dentin. J Endod 2016 Mar;42(3):432-438.

13. Ezoddini-Ardakani F, Nemayandeh SM, Sadrbafghi SM, Hajihashemi S, Emami M, Kahtouei FG, Hadiani L, Ahmadieh MH, Moeini M, Razavi SH, et al. Diagnostic value of dental pulp stones in the early diagnosis of ischemic heart diseases. Health 2015 Mar;7(3):336-345.

14. Vibhute NK, Anikhet HV, Rajendra TD, Puja PB, Aditi M. Hard facts about stones: pulpal calcifications: a review. J Pat Care 2016 Jan;2(1):1.

15. Caviedes-Bucheli J, Moreno JO, Ardila-Pinto J, Del ToroCarreño HR, Saltarín-Quintero H, Sierra-Tapias CL, MaciasGomez F, Ulate E, Lombana-Sanchez N, Munoz HR. The effect of orthodontic forces on calcitonin gene-related peptide expression in human dental pulp. J Endod 2011 Jul;37(7): 934-937. 